\section{A 13-amino-acid motif in the cytoplasmic domain of FcyRIIB modulates B-cell receptor signalling}

\author{
Tatsushi Muta, Tomohiro Kurosaki, \\ Ziva Misulovin, Mercedes Sanchez, \\ Michel C. Nussenzweig \& Jeffrey V. Ravetch
}

Nature 368, 70-73 (1994)

IN this letter we neglected to mention in our citation of ref. 13 that Amigorena et al.' had previously expressed in IIA1.6 cells deletion mutants of $\mathrm{mFc} \gamma \mathrm{RII}-\mathrm{B} 1$ and $\mathrm{B} 2$ that did or did not include the 13-amino-acid cytoplasmic domain motif analysed in our report. The ability of these mutants to attenuate mIginduced B-cell activation was correlated with the presence of this region, suggesting its functional involvement in regulating the activation process. It has also been brought to our attention that Choquet et al. ${ }^{2}$ used this approach to suggest that the regulatory activity could be localized to the YSLL motif contained within the 13-amino-acid region and that the inhibition of $\mathrm{mIg}$-induced activation by mFc $\gamma$ RII affects the influx of extracellular $\mathrm{Ca}^{2+}$ We apologize for these oversights.

1. Amigorena. S. et al. Science 256, 1808-1812 (1992).

2. Choquet, D. et al. J. Cell Biol. 121, 355-363 (1993).

\section{CORRECTION}

\section{Laser action in strongly scattering media}

\section{N. M. Lawandy, R. M. Balachandran, A. S. L. Gomes \& E. Sauvain}

Nature 368, 436-438 (1994)

WE omitted to acknowledge that A.S.L.G. was partially funded by the CNPq Brazilian Agency during this work, undertaken while on sabbatical leave from the Departamento de Fisica, Universidade Federal de Pernambuco, Recife PE 50730, Brazil.

\section{ERRATUM}

\section{Soil acidification and nitrogen saturation from weathering of ammonium-bearing rock}

\section{Randy A. Dahigren}

Nature 368, 838-841 (1994)

THE elemental pool sizes shown on the $y$-axis of Fig. 2 (right panel) of this letter should have been given in units of $\mathrm{kg} \mathrm{ha}^{-1}$, and not ' $\mathrm{Mg} \mathrm{ha}^{-1}$ ' as published.
Pi.f.s. follow these guidelines so that your manuscript may be handled expeditiously.

Nature is an internationai journal covering all the sciences. Contributors should therefore bear in mind those readers who work in other fields and those for whom Fnglish is a second language. and write clearly and simply. avoiding unnecessary technical terminology. Space in the journal is limited. making competition for publication severe. Brevity is highly valued. One printed page of Nature, making competition for publication severe. Brevity is
without display items, contains about 1,300 words.

Manuscripts are selected for publication according to editorial assessment of their suitability and Mantuscripts are selected for publication according to cditorial assessment of their suitability and reports from independent referees. They can be sent to London or Washington and should be
addressed to the Editor. Manuscripts may be dealt with in either office, depending on the subject matter. and will where necessary be sent between offices by overnight courier. High priority cannot be given to presubmission enquiries: in urgent cases they can be made in the form of a one-page ax. All manuscripts are acknowledged on receipt but fewer than half are sent for revicw. Those that are not reviewed are returned as rapidly as possible so that they may be submitted elsewhere without deliay. Contributors may suggest reviewers: limited requests for the exclusion of specific reviewers are usually heeded. Manuscripts are usually sent to two or three reviewers, chosen for their expertise rather than their geographical location. Manuscripts accepted for publication are processed from the L ondon office.

Nature requests authors to deposit sequence and crystallographic data in the databases that exist for this purpose.

Once a munucript is accepted for publication, contributors will receive proofs in about 4 weeks. Nutures staff will edit manuscripts with a vicw to brevity and clarity, so contributors should check proofs carefully. Manuscripts are generally published 2-3 weeks after receipt of corrected proofs Nattre does not exact page charges. Contributors receive a reprint order form with their proofs reprint orders are processed after the manuscript is published and payment received.

\section{Categories of paper}

Review Articles survey recent developments in a ficid. Most are commissioned but suggestions are welcome in the form of a onc-page synopsis addressed to the Reviews Coordinator. Length is negotiable in advance.

Progress articles revicw particularly topical developments for a nonspecialist readership. They do not exceed 4 pages in length. Suggestions may be made to the Reviews Coordinator in the form of a brict synopsis.

Articles are research reports whose conclusions are of general interest and which are sufficiently rounded to be a substantial advance in understanding. They should not have more than 3.000 words of text (not including figure Iegends) or more than six display items and should not occupy more that five pages of Naturc.

Articles start with a heading of 5080 words written to advertise their content in general terms, to which editors will pay particular attention. The heading does not usually contain numbers, abbreviations or measurements. The introduction to the study is contained in the first two or three paragraphs of the article, which also briefly summarize its results and implications. Articles have fewer than 50 references and may contain a few short subheadings.

Letters to Nature are short reports of outstanding novel findings whose implications are general and important enough to be of interest to those outside the field. Letters should have 1,000 or fewer words of text and four or fewer display items. The first paragraph describes, in not more than 150 words and without the use of abbreviations, the background, rationale and chief conclusions of the words and without the use of abbreviations, the background, rationale and chief conclustons of the
study for the particular benefit of non-specialist readers. Letters do not have subheadings and contain ewer than 30 references.

Commentary articles deal with issues in, or arising from, research that are also of interest to readers outside research.

News and Vlews articles inform nonspecialist readers about new scientific advances, sometimes in the form of a conference report. Most are commissioned but proposals can be made in advance to the News and Views Editor.

Scientific Correspondence is for discussion of topical scientific matters. including those published in Nature, and for miscellaneous contributions. Priority is given to letters of fewer than 500 words.

\section{Preparation of manuscripts}

Al! manuscripts should be typed, double-spaced, on one side of the paper only. An original and four copies are required, each accompanied by artwork. If photographs are included, five sets or originals are required: for line drawings. one set of originals and four good-quality photocopies are acceptable. Reference lists. figure legends and tables should all be on separate sheets, all of which should be double-spaced and numbered. Three copies of reicvant manuscripts in press or submitted for publication elsewhere should be included with submitted manuscripts, clearly marked as such. live copies of revised and resubmitted manuscripts, labelled with their manuscript numbers, are Five copies of revised and resubmitted manuscripts. labelled with their
required. together with five copies of a letter detailing the changes made.

Titles are brief and simple. Active verbs, numerical values, abbreviations and punctuation are to be Titles are brief and simple. Active verbs, numerical values, abbreviations and

Artwork should be marked individually and clearly with the author's name and, when known, the manuscript number. Ideally, no figure shoukd be larger than 28 by $22 \mathrm{~cm}$. Figures with several parts are to be avoided and are permitted only if the parts are closely related, either experimentally or logically. Unlettered originals of photographs should be provided. Suggestions for cover illustrations, with captions and labelled with the manuscript number, are welcome. Original artwork is returned when a manuscript cannot be published.

Protein nucleotide sequences should ideally be in the three-letter and not the single-letter code for amino acids. One column width of Nature can accommodate 20 amino acids or 60 base pairs. Colour artwork. A charge of $£ 500$ per page is made as a contribution towards the cost of reproducing colour figures. Inability 10 pay these costs will not prevent publication of essential colour figures if tho crito cover from their galley proofs.

Figure legends should not exceed 300 words and ideally should be shorter. The figure is described first. then, briefly, the method. Reference to a method published elsewhere is preferable to a full description. Methods are not described in the text.

References are numbered sequentially as they appear in the text. followed by those in tables and finally by those in figure legends. Only papers published or in the press are numbered and included in the reference list. All other forms of reference should be cited in the text as a personal communication. manuscript submitted or in preparation. Text is not included in reference lists. References are abbreviated according to the World list of Scicmific Periodiculs (Butterworths. London, 1963-65). The first and last page numbers are included: reference to books includes publisher, place and date.

Abbreviations, symbols, units and Greek letters should be identified the first time they are used Acronyms should be avoided whenever possibie and, if used, defined. Footnotes are not used in the tex

Acknowledgements are brief and appear after the reference list: grant and contribution numbers are not allowed.

Supplementary information is material relevant to Articles or Letlers which cannot, for lack of space. be published in full, but which is available from Nature on request

Submission. Manuscripts can be sent to the Editor at 4 Little Essex Street. London WC2R 3LF. UK or at 1234 National Press Building, Washington. DC 20045, USA. A telephone and fax number should be included. Manuscripts or proofs sent by air courier to London should be declared as 'manuscripts' and 'value $\$ 5$ ' to prevent the imposition of import duty and value-added tax. 